\title{
Standardization of elective tracheostomies at the Central Institute of the Hospital das Clínicas in São Paulo during the COVID-19 pandemic
}

\section{Padronização da realização de traqueostomias eletivas no Instituto Central do Hospital das Clínicas de São Paulo durante a Pandemia de COVID-19}

Carlos Augusto Metidieri Menegozzo, TCBC-SP1i; Sérgio Samir Arap, TCBC-SP2; Alessandro Wasum Mariani ${ }^{3}$; Hélio Minamoto ${ }^{3}$; Rui Imamura ${ }^{4}$; Ricardo Ferreira Bento4; Paulo Manoel Pêgo-Fernandes33; Luiz Paulo Kowalski, TCBC-SP2; Edivaldo Massazo UTIYAMA, TCBC-SP'1.

\section{A B S T R A C T}

The COVID-19 Pandemic has resulted in a high number of hospital admissions and some of those patients need ventilatory support in intensive care units. The viral pneumonia secondary to Sars-cov-2 infection may lead to acute respiratory distress syndrome (ARDS) and longer mechanical ventilation needs, resulting in a higher demand for tracheostomies. Due to the high aerosolization potential of such procedure, and the associated risks of staff and envoirenment contamination, it is necesseray to develop a specific standardization of the of the whole process involving tracheostomies. This manuscript aims to demonstrate the main steps of the standardization created by a tracheostomy team in a tertiary hospital dedicated to providing care for patients with COVID-19.

Keywords: General Surgery. Thoracic Surgery. Trachea. Elective Surgical Procedures.

\section{INTRODUCTION}

O ne of the major concerns regarding the Sars-Cov-2 infection is the unfavorable evolution requiring ICU and the risk of overcrowding. Studies display different figures, but up to $26.4 \%$ of patients may need admission to Intensive Care Units (ICU) ${ }^{1}$. Six to $42 \%$ of patients infected with Sars-Cov-2 require invasive mechanical ventilation, and up to $11.5 \%$, extracorporeal membrane oxygenation $(\mathrm{ECMO})^{1-3}$. Depending on the population studied, these numbers may be even greater. A study of 24 patients admitted to the ICU showed that $75 \%$ required mechanical ventilation ${ }^{4}$.

The length of stay of patients with COVID-19 in the ICU is variable and dependent on the patient's clinical conditions and the resources of each unit. Bhatraju et al. published a small series of cases showing an average of 10 days in the $\mathrm{ICU}^{4}$. Prolonged patient stay can be an additional factor in the collapse of institutional resources.

Tracheostomy is a procedure commonly indicated in patients with prolonged orotracheal intubation and considered at risk in patients with some respiratory infections. In a systematic review, tracheostomy was considered the second most aerosolgenerating procedure ${ }^{5}$. In this context, the creation of a group dedicated to performing tracheostomies during the COVID 19 pandemic is essential, since the group's experience and training can result in shorter procedure time and greater adherence to contamination precautions ${ }^{2}$.

This article aims to present the institutional protocol developed at the Central Institute of the Hospital das Clínicas, Faculty of Medicine, University of São Paulo, a tertiary center dedicated exclusively to the care of patients with suspected or confirmed infection during the COVID-19 pandemic. 


\section{PROTOCOL DEVELOPMENT}

The Tracheostomy Team (TT) at the Central Institute of the Hospital das Clínicas (ICHC) is composed of doctors from the General Surgery, Thoracic Surgery, Head and Neck Surgery, and Otorhinolaryngology teams.

In view of the COVID-19 pandemic and the published recommendations regarding tracheostomies and other surgical procedures, ${ }^{2,6-9}$, including those arising from experience with the SARS epidemic ${ }^{10,11}$, it was necessary to modify and standardize the various steps related to performing tracheostomy. In view of the contamination precautions, attention should be paid to some modifications of the traditional technique, the preparation of the team, and the materials.

\section{INSTITUTIONAL PROTOCOL}

\section{1) General determinations}

a. Every case will be assessed jointly by the ICHC Tracheostomy team and the Intensive Care team to decide on the indication. This team is composed of specialists in General Surgery, Head and Neck Surgery, Thorax Surgery and Otorhinolaryngology;

b. There is no evidence of benefits of early tracheostomy in these patients, therefore, tracheostomies will be performed preferably after 14 days of intubation, considering a possible reduction in viral load and risk of contamination ${ }^{12}$;

c. The technique adopted should be the one with which the attending team has more experience, since there is no evidence of difference between open and percutaneous techniques as to contamination. If the technique chosen is percutaneous, we standardized the use of ultrasound as a guide rather than bronchoscopy, to avoid contamination risks associated with its use $\mathrm{e}^{7,10 \text {; }}$

d. The objectives of the standardization described in this document are to not harm the patient and to optimize the procedure time and results, minimizing the risks for the professionals involved.

\section{2) Criteria to indicate the ultrasound-guided percutaneous technique}

a. Distance between the cricoid cartilage and the sternal bone should allow for proper placement of the transducer (usually at least $3 \mathrm{~cm}$ or 2 fingers);

b. Possibility of cervical hyperextension;

c. Absence of large vessels or arterial flow pattern in the puncture path (observed by ultrasound).

\section{3) Location for the procedure}

a. Ideally, an isolated room with lower pressure than the corridor. If unavailable, use a room with closed doors and no laminar flow;

b. Procedures performed at the Operating Room:

c. The team must dress up and prepare the materials INSIDE the room where the procedure will be performed and according to the institutional flow of surgeries at the Central Institute;

i. The surgical tables must be assembled with all the materials to be used;

ii. The patient should only be called as soon as all teams are properly prepared, with all materials in the room (including ultrasound equipment, if necessary).

c. Procedures performed in the ICU:

i. The dressing, the preparation of the materials and the assembly of the surgical tables must occur OUTSIDE the patient's bed room;

ii. Professionals should enter the room in an organized and standardized manner.

\section{4) Staff (ideally limited to 4 people in the room to minimize exposure)}
a. Surgeon; 
b. Assistant;

c. Anesthesiologist:

i. In addition to anesthesia, will be in charge of airway care (removal of the orotracheal tube).

d. Nursing Technician:

i. In charge of administering medications and preparing the necessary equipment.

Other professionals such as physiotherapists, who are often responsible for adjusting the mechanical ventilator, should leave the room before performing the procedure.

\section{5) Pre-procedure preparation}

a. Checking the patient and the tracheostomy indication;

b. Check the necessary materials and the availability of Personal Protective Equipment (PPE). In the absence of any of these, adjourn the procedure:

i. Ensure the presence of more than one type of cannula size.

c. Pre-procedure meeting to review all steps of the procedure and management;

d. Determination of ventilatory parameters and adjustment of the mechanical ventilator for preoxygenation;

e. Suggested preparation of sedation medications:

i. Propofol in pump or bolus (prepare 10$20 \mathrm{~mL}$ );

ii. Ketamine $1 \mathrm{mg} / \mathrm{kg}$ (mainly if bolus propofol) + benzodiazepine;

iii. Pump or bolus fentanyl (prepare $5-10 \mathrm{~mL}$ );

iv. Long-lasting muscle relaxant (rocuronium prepare 2 ampoules) to reduce the risk of coughing and aerosolization.

\section{6) Paramentação}

a. Follow the recommendations of the Hospital Infection Control Center (HICC). Every professional who enters the room must wear a hat, foot protection, PFF3 or N95 mask and a face shield. Apron and gloves (sterilized for the surgical team and regular for the anesthetist and nursing technician) must be worn inside the procedure room. In case $s$ in which face shields cannot be used, goggles and an additional surgical mask (in front of the N95 or PFF3) can be used; however, they do not maintain the same level of protection.

\section{7) Materials}

a. Airway:

i. Video laryngoscope (preference) or laryngoscope;

ii. $20 \mathrm{~mL}$ syringe for deflating the cuff;

iii. Connection with antiviral filter.

b. The table must contain:

i. Minor surgery box or similar, containing Halsted forceps;

ii. Scalpel blade number 11 or 15;

iii. 3-0 Nylon suture for cannula fixation;

iv. 4-0 Cotton suture;

v. 4 packs of dry gauze;

vi. 1 packet of wet gauze with alcoholic chlorhexidine;

vii. 1 vile of local anesthetic;

viii. 1 pink or red needle for aspiration of the anesthetic;

ix. 1 black needle for anesthetic injection;

$x$. Non-fenestrated tracheal cannulas for hospital use (with cuff and without internal cannula) numbers 8, 9 and 10;

xi. Xylocaine gel for lubrication of the tip of the tracheal cannula;

xii. One $20 \mathrm{~mL}$ syringe connected to the tracheal cannula balloon;

xiii. Connection with antiviral filter; xiv. Suction material (closed circuit);

$x v$. For the Percutaneous technique:

1. Percutaneous tracheostomy kit (preference for dilation-free methods).

2. One $20 \mathrm{~mL}$ syringe with distilled water or saline for the ultrasound transducer (in the absence of sterile gel).

3. The ultrasound equipment must be protected with a disposable plastic cover. 
4. The transducer and cable must be enclosed in a disposable sterile plastic wrap.

c. All equipment on the operating table must be ready for use;

d. 4 sterile drapes.

\section{8) Entry of professionals into the room - Procedure in the ICU}

a. Ultrasound-Guided percutaneous tracheostomy

i. Main Surgeon:

1. Enters the room with the operating table and the covered transducer, positioning it to the patient's right.

2. Starts asepsis and placement of sterile drapes in a conventional manner.

3. This surgeon will perform the procedure and the handling of the ultrasound, simultaneously.

ii. Airway Physician:

1. Enters the room his/her materials, medications and ultrasound equipment, following the Main Surgeon.

2. Positions the ultrasound equipment to the patient's left at the height of the greater trochanter and connects the transducer.

3. Positions his/her airway materials and medications.

4. Administers medications.

b. Conventional tracheostomy (open):

i. Airway Doctor:

1. Enters the room with his/her materials, with the aspirated medications.

2. Positions his/her airway materials and medications.

3. Modifies mechanical ventilators parameters.

4. Administers medications.

ii. Assistant Physician, to the patient's left:

1. Starts asepsis.

iii. Main Surgeon:

1. Enters the room with the operating table and stands at the patient's right side.

\section{9) Operative steps - Ultrasound-Guided Percutaneous Tracheostomy}

a. Identification of cervical structures and assurance of the absence of large vessels or arterial flow in the puncture path. If there is an unfavorable, previously unnoticed anatomical condition, switch the technique to conventional (open);

b. Identification of the puncture site, between the $2 \mathrm{nd}$ and the 3rd, or 3rd and 4th, tracheal rings;

c. Local anesthesia guided by ultrasound and skin incision;

d. Suspension of ventilation, deflation of the cuff and traction of the orotracheal tube guided by ultrasound, keeping the tip of the tube at the height of the 1st tracheal ring. As soon as possible, re-inflate the cuff and re-fixate the tube. Resume mechanical ventilation if necessary and suspend it again before tracheal puncture;

e. Centralized and perpendicular, ultrasoundguided tracheal puncture until air aspiration, confirming intratracheal positioning;

f. Passage of guide wire;

g. Passage of first dilator;

h. Passage of the second dilator/dilation with a Griggs forceps (in this step, if it is necessary to ventilate the patient, occlusion of the tracheal dilator orifice with finger). Keep occlusion until mechanical ventilation stops, with time for expiration;

i. The passage of the tracheal cannula must be performed in apnea, inflating the cuff immediately after;

j. Disconnection of the mechanical ventilator from the occluded orotracheal tube and connection to the tracheal cannula;

k. Confirmation of intratracheal positioning with capnography. In the absence of a capnograph, 
confirm the position observing bilateral pleural sliding;

I. Conformation of absence of intraoperative complications (pneumothorax and subcutaneous emphysema) with ultrasound examination;

$m$. Dressing with gauze around the cannula and fixation to the skin with 3-0 Nylon or specific tapes;

n. Discard of disposable materials and appropriate conditioning of permanent materials.

\section{0) Operative steps - Conventional (open) tracheostomy}

a. Operative steps:

i. Skin incision and dissection of the tissues according to the usual technique, avoiding the use of electrocautery due to the risk of particulate smoke formation. Preference to ligatures for hemostasis;

ii. Before the tracheal incision: ensure the patient's paralysis and adequate ventilation. Stop ventilation and shut off any flow. Ensure sufficient time for expiration with the expiratory valve open;

iii. Advance the occluded orotracheal tube and inflate the cuff below the site proposed for the tracheostomy, with pressure levels above the usual. Restore ventilation, confirm adequate pre-oxygenation, and then stop ventilation again, ensuring time for complete expiration, and occlude the tube;

iv. Create the tracheal window, minding the cuff, deflate it and pull the tube until the tip is proximal to the tracheal window. Ensure that the window is large enough to allow easy insertion of the tracheal cannula;

v. After insertion of the cannula, immediately inflate the cannula cuff with the syringe already attached to the cuff channel. Remove the introducer and attach connection with the antiviral filter to the cannula and the circuit. Restore ventilation and confirm positioning with capnography (avoid using the stethoscope);

vi. Fix the tube with suture or with specific tapes.

\section{1) Disrobing}

a. Personal disrobing and removal of plastic covers (the undressing must follow the care recommended by the HICC team);

b. Equipment hygiene.

\section{2) Clean area}

a. After disrobing, it is recommended that the team involved in the procedure use a shower for body cleaning;

b. Description of the procedure and orientation on postoperative care;

c. Completion of the questionnaire for the database.

\section{3) Post-procedure (ICU and others)}

a. Multiprofessional Team:

i. Train care during transfer;

ii. A member of the local team must be responsible for the tracheostomy during changes in decubitus and pronation;

iii. Avoid humidified oxygen, use only filters;

iv. Aspiration of airways always in a closed circuit;

v. Periodically check the cuff, keeping it always inflated in COVID positive patients (avoid cuff hypoinflation as much as possible);

vi. Avoid dressing changes, unless there are clear signs of infection.

b. Cannula exchange:

i. Avoid switching the cannula before 7 to 10 days, giving preference to a period of lower viral load7;

ii. Use full PPE for exchanges;

iii. Follow the same guidelines on the flow of 
the mechanical ventilator for exchanges. Deflate the cuff only with the flow off and inflate the cuff of the new cannula immediately after insertion.

c. Weaning from the Intensive Care Unit:

i. Ward dedicated to COVID, tracheostomized patients, with trained nursing staff;

ii. Use of cannulas without fenestrations until the COVID exam is negative;

iii. Change the cannula after 30 days.

\section{CONCLUSION}

Tracheostomies are procedures of high contamination risk, given the potential for aerosolization. This protocol may change over the next few weeks and, if reproduced in other services, may require adaptations to local realities. The standardization described in this article aims to reduce the time spent in the procedure environment and the risk of aerosolization, reinforcing care in each stage of assistance.

\title{
R E S U M O
}

\begin{abstract}
A pandemia da COVID-19 tem gerado um número elevado de internações hospitalares e muitos pacientes são admitidos nas unidades de terapia intensiva para suporte ventilatório invasivo. A pneumonia viral provocada pelo Sars-cov-2 pode resultar na síndrome da disfunção respiratória aguda (SDRA) e em um tempo prolongado de ventilação mecânica, gerando uma demanda maior de traqueostomias. Diante do alto potencial de aerossolização desse procedimento, com risco de contaminação da equipe e do ambiente, é necessário criar uma padronização especifica de todo o processo que envolve essa cirurgia. Este artigo visa demonstrar as principais etapas dessa padronização desenvolvida por um equipe dedicada à realização de traqueostomias em um hospital terciário dedicado ao atendimento de pacientes com suspeita ou confirmação de COVID-19.
\end{abstract}

Palavras chave: Cirurgia Geral. Cirurgia Torácica. Procedimentos Cirúrgicos Eletivos.

\section{REFERENCES}

1. Wu C, Chen X, Cai Y, Xia J, Zhou X, Xu S, et al. Risk factors associated with acute respiratory distress syndrome and death in patients with Coronavirus disease 2019 pneumonia in Wuhan, China. JAMA Intern Med. 2020 Mar [acessado 07 Apr 2020];e200994. Disponível em: https:// jamanetwork.com/journals/jamainternalmedicine/ fullarticle/2763184. Acessado em 07/04/2020.

2. Tau JK, Khoo ML-C, Loh WS. Surgical considerations for tracheostomy during the COVID-19 pandemic lessons learned from the severe acute respiratory syndrome outbreak. JAMA Otolaryngol Head Neck Surg. 2020 Mar [acessado 04 Apr 2020]. Disponível em: https://jamanetwork.com/journals/ jamaotolaryngology/fullarticle/2764032. Acessado em 07/04/20203.

3. Yang $X, Y u Y, X u$ J, Shu H, Xia J, Liu H, et al. Clinical course and outcomes of critically ill patients with SARS-CoV-2 pneumonia in Wuhan, China: a single-centered, retrospective, observational study. Lancet Respir Med. 2020 [acessado 07 Apr 2020]; 8(5):475-81. Disponível em: https://www.
thelancet.com/journals/lanres/article/PIIS22132600(20)30079-5/fulltext.

4. Bhatraju PK, Ghassemieh BJ, Nichols M, Kim R, Jerome KR, Nalla AK, et al. Covid-19 in critically III patients in the Seattle Region - case series. N Engl J Med. 2020 [acessado 10 Apr 2020]; 382(21):201222. Disponível em: https://www.nejm.org/doi/ full/10.1056/NEJMoa2004500.

5. Tran $K$, Cimon $K$, Severn $M$, Pessoa-Silva $C L$, Conly J. Aerosol generating procedures and risk of transmission of acute respiratory infections to healthcare workers: A systematic review. PLoS One. 2012;7(4):e35797.

6. Correia MITD, Ramos RF, von Bahten LC. Os cirurgiões e a pandemia do COVID-19. Rev Col Bras Cir. 2020;47(1): e20202536

7. Givi B, Schiff BA, Chinn SB, Clayburgh D, lyer NG, Jalisi S, et al. Safety Recommendations for Evaluation and Surgery of the Head and Neck during the COVID-19 Pandemic. JAMA Otolaryngol Head Neck Surg. 2020 Mar 31 [acessado 10 Apr 2020]. Disponível em https://jamanetwork.com/ journals/jamaotolaryngology/fullarticle/2764032.

8. Lima DS, Ribeiro Júnior MF, Vieira-Jr HM, 
Campos T, Di Saverio S. Alternativas para o estabelecimento de via aérea cirúrgica durante a pandemia de COVID-19. Rev Col Bras Cir. 2020;47(1):e20202549.

9. Chao TN, Braslow BM, Martin ND, A CA, Atkins JH, R HA, Chalian AA, Atkins JH, Haas AR, Rassekh $\mathrm{CH}$; Guidelines from the COVID-19 Tracheotomy Task Force, a Working Group of the Airway Safety Committee of the University of Pennsylvania Health System. Ann Surg. 2020 May [acessado 2020 Apr 12]; 271. Disponível em: https://journals.Iww. com/annalsofsurgery/Documents/Tracheotomy in ventilated patients with COVID19.pdf.

Received in: 15/04/2020

Accepted for publication: 12/05/2020

Conflict of interest: não.

Funding source: none.
10. Tien $H C$, Chughtai $T$, Jogeklar $A$, Cooper $A B$, Brenneman $F$. Elective and emergency surgery in patients with severe acute respiratory syndrome (SARS). Can J Surg. 2005;48(1):71-4.

11. Chee VWT, Khoo MLC, Lee SF, Lai YC, Chin NM. Infection control measures for operative procedures in severe acute respiratory syndrome-related patients. Anesthesiology. 2004;100(6):1394-8.

12. Peiris JSM, Chu CM, Cheng VCC, Chan KS, Hung IFN, Poon LLM, et al. Clinical progression and viral load in a community outbreak of coronavirusassociated SARS pneumonia: a prospective study. Lancet. 2003;361(9371):1767-72.

\section{Mailing address:}

Carlos Augusto Metidieri Menegozzo

E-mail: carlos.menegozzo@hc.fm.usp.br/carlos.menegozzo@ hc.fm.usp.br

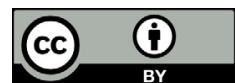

